\title{
Study on the Feasible Strategies of Overall Construction Project Management in the Ecological Industrial Community of Sustainable Development Based on Ecosystem Theory
}

\author{
I-Chan Kao \\ General Education Center, Open University of Kaohsiung. \\ No. 436, Daye North Rd., Siaogang Dist., Kaohsiung City, Taiwan \\ kic0929@ouk.edu.tw
}

Keywords: Ecosystem theory; Community construction; Project management; Sustainable development.

\begin{abstract}
Taking Linhai Industrial Park contaminated by heavy industry in Kaohsiung, Taiwan as a case, this study analyzes the feasibility of promoting overall construction project management in industrial pollution community based on ecological theory. Aiming at the surrounding community environment of the industrial park, it summarizes the formative factors of overall construction project management in the community and the fields of ecological environment analysis, and proposes some feasible strategies such as promoting the overall construction of the community to construct the honor and value of "life community", flipping the life image of heavy industrial community with art aesthetics, the cooperation of industrial circles, government departments, schools and nongovernmental organizations to create a new community and integrating regional resources to improve the overall construction benefits of the community, so as to complete the objective of the overall construction project management of ecological industrial community as expected.
\end{abstract}

\section{Introduction}

Ecosystem theory means that the environment (or natural ecology) is "a group of nested structures, just like a Russian matryoshka". In other words, the developing individuals are in the middle of or nested in several environmental systems from the immediate environment (such as family, community, school) to the indirect environment (like city, country, culture). Each system interacts with other systems and individuals, influencing many important aspects of development (Bronfenbrenner, 1979).

Kaohsiung City of Taiwan is a heavy industrial city in the southeast of China. "Kaohsiung Linhai Industrial Park" where there are many high-pollution industries including iron and steel, petrochemical, power plants and cement, emits large amounts of air pollutants as well as great quantities of greenhouse gases. Kaohsiung's greenhouse gas emission reaches up to 5.659 million tons (in 2015, the energy sector only calculated the energy use of the power plant, excluding the emission amount of electricity sold), and Kaohsiung's per capita emission reaches up to 20.37 metric tons per year (2015), far higher than Taiwan's per capita emission of 10.7 metric tons per year and the global average of 4.9 metric tons per year (Kaohsiung Climate Change and Sustainable Action
Network, 2018). Therefore, we aim to create a new sustainable green eco-friendly community and clearly define "low-carbon" as a community-building vision, hoping to get a livable and sustainable environment in the future.

\subsection{Research purposes}

Based on the above research background and motivation, the purposes of this study are listed as follows.

1.1.1 To explore the situation analysis of community construction project management.

1.1.2 To explore the methods and processes of the overall construction of industrial ecological community by taking Linhai industrial district of Kaohsiung in Taiwan as an example.

1.1.3 To construct feasible strategies of construction project management in industrial community of sustainable development.

\subsection{Research methods}

This study first uses literature analysis method to explore the implications of ecosystem theory, project management knowledge system and overall community construction, and then constructs feasible strategies of 
overall construction project management in the ecological industrial community of sustainable development by taking Linhai Industrial Park in Kaohsiung, Taiwan as an example.

\section{Literature review}

\subsection{Literature review of ecosystem theory}

The appearance of community development is the mutual reconciliation of people and the environment. The emphasis of community development lies on the rule of man and the interaction between people and the environment. The issue of environment and people is a complex and dynamic perspective that can be interpreted from an ecological point of view. The core of an ecological perspective is the continuous exchanging relationship between organisms or living systems and their environment (Huang Yuanxie, 2004). Ecosystem viewpoint provides a comprehensive, dynamic and interactive theoretical interpretation for community work practices. Through the use of ecological concept, the interaction between systems and the adaptation of individuals and the environment can be understood, and more importantly, the focus of people in context can be conveyed (Bronfenbrenner, 1979).

Introducing the three characteristics of ecosystem into the industrial park, it is found that the industrial park also has the features of diversity, inertia, and flexibility. The diversity represents the industrial park has different types of industries and they cooperate with each other to become a network system similar to the food chain; inertia means that the industrial park itself has operating characteristic or industry type feature, has the ability to resist changes, is not easily subject to external interference to undergone significant changes, and usually has a operation method of certain mode; flexibility represents the management methods of industrial park itself should have the ability to absorb pressure to cope with pressure generated by the changes in the external environment (Cote and Hall, 1995).

\subsection{Literature review of community construction project management}

The "limited resources" emphasized by the community construction project management refer to limited "time" and "cost" resources; the established and unique target vision refers to the "scope of work" that must be implemented and the required "quality of results". The community construction project management must organize the community to construct the allocation and recruitment of human resources, and should apply effective communication and mechanism to build the project team, integrate community construction projects, organize various human resources, material resources and financial resources within and outside the project, complete the verification standards of deliverable results meeting community construction project and meet the needs of stakeholders of community construction project for the project (Qi Anbang, 2005; Xu Chengji, 2004;
IPMA, 2009; Kerzner, 2006; PMI, 2012; Nicholas \& Steyn, 2012; Kao, 2014; Kao, 2018).

\section{Situation analysis of community construction project management}

When community members operate and manage various project businesses, the project management capability of the project members and the maturity of the project management and operation system of the community organizations are the most direct factors influencing the success or failure of the project; followed by the project stakeholders; and finally the external environment of project implementation, including ecological environment, cultural environment, social environment, political environment, international environment and industrial environment (Kao, 2012; Wei Qiujian, 2013).

\subsection{Project management function}

The project management function refers to applying the cognitive performance and skill performance of the project's sponsorship, planning, implementation, control and completion as the items of project management function, and the project management attitude and moral and ethical norms as the functional indicators of human resources development of the overall construction project management in the community (Kao, 2017), to promote the performance of overall construction project management operation in the community.

\subsection{Project management maturity}

Project management maturity is to get the direction of future improvement by understanding the maturity of the organization. The project management maturity model can point out the key points that need to be improved in each level and provide a guidance for the organization, so that the organization can obtain better project management performance (Kao, 2013; Editorial Committee of Taiwan Project Management Association, 2016).

\subsection{Stakeholders}

Community residents are one of the most important stakeholders, whether the goals of community construction project management can be achieved is determined by whether community residents can accept the construction results. In other words, if community residents are unwilling to accept the deliverable results of acceptance projects, even dedicating to the tasks and activities of project management, the achievement to the goal of community construction project cannot be ensured.

\subsection{Micro environment of the community}

The macro environment of the community construction project management includes ecological environment, cultural environment, social environment, political 
environment, international environment and industrial environment

\subsubsection{Ecological Environment}

Poor community air quality may affect the function of respiratory organs, which would be a major obstacle for the community to organize sports competition projects, for the participating people cannot effectively exert their strength, and their health may be damaged.

\subsubsection{Social Environment}

The community promotes "solar power generation project" to reduce the air pollution caused by coal-fired power generation. If this project can obtain the full support and input of community residents, it will help achieve the goal of sustainable community of "photoelectricity green energy".

\subsubsection{Cultural Environment}

In the belief culture of Chinese people, they would set off firecrackers in an idolatrous procession, causing serious air and noise pollution in the community, and this activity is especially popular in the religious activities of the communities in Kaohsiung City. Combined with industrial noise and air pollution, it would cause the community's ecology calamity. Only to change this bad custom can gradually clean up the community's ecological environment.

\subsubsection{Political Environment}

A stable political situation and people living in peace and contentment would create a good environment for community to develop activities; political turmoil would cause unrest in the community and community people often protesting against the society in the streets, causing the dissatisfaction increase of the community residents and their moving away from the community.

\subsubsection{International Environment}

For economies relying on exports, their industrial communities must get the support from international economy and trade, so that industrial production can be continued and community residents can continue to develop careers.

\subsubsection{Industrial Environment}

The Linhai Industrial Park in Kaohsiung is a collection and distribution center for steel and petrochemical industries. If industrial capacity is affected by contraction, the competitiveness and production energy of Linhai Industrial Park's industries would be reduced.

\section{Constructing Feasible Strategies of Overall Construction Project Management in the Ecological Industrial Community of Sustainable Development by Taking Linhai Industrial Park in Kaohsiung, Taiwan as a Case}

\subsection{Promoting the Overall Construction of the Community to Construct the Honor and Value of "Life Community"}

The biggest difference between Linhai Industrial Park in Kaohsiung City of Taiwan and other industrial areas or science and technology industrial parks is that its plant area is closely adjacent to the community, and the community living environment is fully integrated into the operating system of the entire industrial park. Therefore, in the future, the park will conduct overall community construction with the community environment, and integrate the park area, the community and the urban area of Kaohsiung City as a whole to conduct the integration of the industrial park and community resources of Kaohsiung City and the construction of the overall construction system. The practices activating industrial area include establishing plan of innovative governance mechanism, attraction plan of human resources, construction plan of industrial urban area identity awareness, construction of overall visual image aesthetics in the community, construction of scientific and technological communication identification and navigation system, construction of transportation safety system, implementation of environmental protection and environmental education, rehabilitation and reconstruction of drainage system and so on. Activating the industrial zone through the overall communityconstruction approach can promote the further improvement of the industrial zone's vitality and construct the honor and value of "life community" with the community.

\subsection{Flipping the life image of heavy industrial community with art aesthetics}

Since Linhai Industrial Park covers a large area and is closely adjacent to many factory buildings and residential areas, it is very important to clearly identify the locations of the factories and roads in the industrial area. It is necessary to set up maps of nearby factories and streets in the main road entrances in the industrial area, so that visiting people can know their locations and then quickly know their destinations. The old street signs and street lamps in current industrial zone can be rebuilt based on the plan direction of "industrial aesthetics", "local art", "localized visual image" and "energy saving and carbon reduction". In addition, local steel carving artists can be invited to design some visual image works fitting the characteristics of the street signs of the park based on the characteristics of the park, so that the industrial zone can exhibit the street sign features of "flexibility and 
softness" and "beautification and greening", and the street and the city would also take on a new look.

\subsection{Cooperation of industrial circles, government departments, schools and non-governmental organizations to create a new community}

The leaders and principals of government agencies such as the Civil Affairs Bureau, the Social Bureau, the Tourism Bureau and the Labor Bureau of Kaohsiung Municipal Government, Linhai Industrial Park Service Center, Manufacturer Association, Community Development Association, and Community Disadvantaged Care Association covering governments, industries, communities, organizations, schools and the like are invited to join the executive team of this plan to jointly plan the teaching activities of this program, the overall construction work of community landscaping and afforestation and the guidance practice of Linhai Industrial Park, implement identity plan of "Art Oasis Special Zone of Linhai Industrial Park" and organize community service volunteer groups, including Linhai Industrial Park's industrial art beauty, international industrial city expo carnival planning, industrial oasis arts festival banquet plan, multicultural art center construction plan, and communication between the artistic masters of international community in Linhai Industrial Park. They also can jointly carry out the resources recycling of industrial area vendors, community rejuvenation, provide research center for professional artists and local manufacturers, and jointly plan international art zone art expo carnival and international forum for the communication between artistic masters in international industrial communities.

\subsection{Integrating regional resources to improve the overall construction benefits of the community}

Regional resources including Linhai Industrial Park, district offices of various administrative districts, various types of industries, community development associations, community disadvantaged care groups, various types of non-profit organizations, Kaohsiung Foreign sister care association, new residents mutual aid groups, new residents family service center, Social Bureau, Civil Affairs Bureau, Labor Bureau, Tourism Bureau of Kaohsiung Municipal Government, Industrial Bureau of Ministry of Economic Affairs, Linhai Industrial Zone Service Center, Manufacturers Association, Labor Development Agency of Labor Department and Immigration Agency of the Ministry of the Interior are integrated to jointly promote the implementation of this plan. The overall construction of the community in this study is the practice course of applying cross-domain resources integration mode with the regional resources where the communities are located to carry out the community governance of man-building, landscaping, production and culture construction. This plan introduces human resources and material resources of each organization in the plan execution region, hoping to achieve the goal of this plan by integrating various resources across regions.

\section{Conclusion}

To explore the feasible strategies for the overall construction project management of industrial communities based on ecosystem theory, "combination of aesthetics and green elements" and "green energy-saving system research and development" with high value-added in the industrial industry chain should be emphasized. The government needs to propose a transformation conception of economic momentum, including viable business model of brownfield remediation experience, introduction of enterprise development, refined transformation of promoting industry, introduction of funds and incentive measures to establish a clean energy development model, integration of green energy, innovation and research and development, soil pollution remediation, petrochemical uplift, and central resources and incentives support, to seek the best possible way for the development of the park, to improve the transformation economy momentum, accelerate the transformation of industrial parks, transform industrial cities into livable low-carbon new cities, and build a community blueprint of "happy community and sustainable construction".

The overall construction tasks of the ecological industrial community are to develop the sense of purpose, sense of belonging, sense of inputting, adaptive roles and responsibilities, control benchmark, formulate decisions, solve conflicts, establish norms, achieve goals and establish project management experience knowledge base of the overall construction in the community of sustainable development. Therefore, to construct an ecological industrial community, it is necessary to make good use of methods and tools for project management environment analysis of ecosystem theory and industrial ecology, to grasp the opportunities of community development, introduce appropriate project management knowledge systems to cultivate management talents of overall construction project, set up project management office to promote community development policies, improve the maturity of the community construction project management organization, continue to enhance the benefits of community development, and achieve the goal of an ecological industrial community of "benevolence and sustainable development".

\section{References}

1. Editorial Committee of Taiwan Project Management Association (2016). International Project Management Knowledge System 3.0. Kaohsiung: Taiwan Project Management Society

2. Kaohsiung Climate Change and Sustainable Action Network (2018). Mitigation Goal. May 3, 2018,

http://khsclimatechange.com/slowdown.aspx?n wid $=201801290002$ 
3. Kao, I.C (2012). Environmental Analysis of Project Management and the Application of Organizational Patterns in School Organization Development. Journal of Knowledge Economy, 9(2), 170-199

4. Qi Anbang (2005). Modern Project Management. Beijing: University of International Business and Economics Press

5. Xu Chengji (2004). Modern Project Management Textbook. Xinbei: Dr Master Press

6. Huang Yuanxie (2004). The Direction of Community Work: Community Development? Community Construction? Community Development Quarterly, 107, 78-88

7. Wei Qiujian (2013). General Project Management Knowledge System. Taipei: Wunan

8. Bronfenbrenner, U. (1979). The ecology of human development. Cambridge, MA: Harvard University Press

9. Cote, R. and Hall, J. (1995). Industrial park as ecosystems. Journal of Cleaner Production, 3(12), 41-46.

10. IPMA(2009)

ICB

http://ipma.ch/resources/ipmapublications/ipma-competence-baseline/
11. Kao, I.C.(2013). Application of Definition and Role Analysis of Project Stakeholders in the Human Resource Development of School Project Management Strategies. Storage Management Solutions, Issue 6, 158-190

12. Kao, I.C.(2014) . Exploration and Analysis on the Development and Implementation of Community Development Project Management Indicators.. Advances in Engineering Education, 5(4),177-217

13. Kao, I.C.(2017). A study on the development of the "Taiwan project management competence scale, MATEC Web of Conferences, 119, 01037. DOI: $10.1051 /$ matecconf/2017119010

14. Kao, I.C.(2018)。The Empirical Analysis of Project Management of Adult Education and Community Development. Taipei: Han Lu

15. Kerzner, H., (2006). Project Management: $A$ System Approach to Planning, Scheduling, and Controlling, gh $^{\text {th }}$ Edition, NY: John Wiley \& Sons, Inc.

16. Nicholas, J.M. \& Steyn, H.(2012). Project Management for Engineering Business and Technology $4^{d}$, Taylor \& Francis Group, LLC.

17. PMI(2012). A Guide to the Project Management Body of Knowledge $5^{d}$. Pennsylvania: PMI. 